\title{
Historiografía israelí y la creación del Estado de Israel
}

\section{Israeli Historiography and the Creation of the State of Israel}

\author{
JUAN DAVID ECHEVERRY TAMAYO \\ Universidad Nacional Autónoma de México, México
}

Resumen: La nación, como cualquier otro sistema de organización humana, debe ser entendida como un discurso con un origen determinado y no como un fenómeno objetivo, teleológico y primigenio. Esto quiere decir que, desde la llegada de grandes olas de migrantes judíos a Palestina con el objetivo de erigir un Estado-nación en ese territorio, intelectuales y políticos sionistas e israelíes se han encargado de construir explicaciones subjetivas para justificar sus demandas y sus intereses, las cuales se tradujeron en paradigmas historiográficos que dieron sentido a la identidad, la cultura y el vínculo con la tierra de la población israelí. Con esto en mente, en este trabajo se hará un balance de las principales corrientes historiográficas que han definido la creación del Estado israelí, en un intento de aclarar cómo surgió la ideología que posibilitó la creación de Israel y de qué manera la historiografía se ha adaptado a los diferentes momentos del conflicto palestino-israelí.

Recepción: 15 de febrero de 2020. / Aceptación: 18 de enero de 2021. 
Palabras clave: historiografía israelí; conflicto palestino-israelí; historia de Israel; Medio Oriente; nacionalismo israelí.

Abstract: The nation, like any other system of human organization, must be understood as a discourse with a specific origin and not as an objective, teleological and primal phenomenon. In this sense, since a large influx of Jewish migrants came to Palestine to build a nationstate in this territory, Zionist and Israeli intellectuals and politicians have constructed subjective explanations to justify their demands and interests. These turned into historiographic paradigms that gave meaning to the Israeli population's identity, culture, and links to the land. With this in mind, this study strikes a balance between the main historiographical trends that have defined the creation of the Israeli State. It seeks to clarify the Israel's underlying ideology and to explore historiography's adaptations at different junctures of the Israeli-Palestinian conflict.

Keywords: Israeli historiography; Israeli-Palestinian conflict; history of Israel; Middle East; Israeli nationalism.

\section{Introducción}

Con el fin de explicar cómo se desarrolló el pensamiento nacionalista que permitió la creación del Estado de Israel, este trabajo partirá de los planteamientos de Gregory J. Lobo en su libro Colombia: algo diferente de una nación (2009), acerca de la naturaleza y el origen de la nación como sistema de organización humana. Esta obra sigue la teoría del discurso planteada por académicos como Louis Althusser, Ernesto Laclau, Michel Foucault, Clifford Geertz, Pierre Bourdieu, Chantal Mouffe, Peter L. Berger y Thomas Luckmann, para llegar a la conclusión de que la nación, como cualquier otro sistema de organización humana, debe ser entendida como un discurso con un origen determinado y no como un fenómeno objetivo, teleológico y primigenio. En este sentido, según lo expresado por Lobo $(2009,7)$, es necesario mencionar que la 
idea de una nación judía, como cualquier otra idea de nación, es una construcción discursiva e identitaria que, si bien no posee un origen, una validez y un fundamento incuestionable, proviene de la necesidad de toda comunidad humana de afrontar las condiciones precarias de la realidad mediante el uso de construcciones discursivas, ideológicas e institucionales que se opongan al caos.

Asimismo, Benedict Anderson $(1993,21)$ argumenta que la nación es una construcción social específica cuya naturaleza no es estable debido a que está sometida a todo tipo de dinámicas históricas. Según Anderson, todo análisis sobre la nación y el nacionalismo debe "considerar con cuidado cómo han llegado a ser [éstos] en la historia, en qué formas han cambiado sus significados a través del tiempo y por qué, en la actualidad, tienen una legitimidad emocional tan profunda". Todo aquello implica que: $i$ ) la nación es un concepto que posee una historicidad particular; ii) el concepto de nación está sometido a una gran variabilidad en sus significados, y iii) la nación está íntimamente ligada a la generación de vínculos de carácter sentimental entre miembros de un colectivo. En consecuencia, a lo largo de su historia, los israelíes han construido explicaciones subjetivas tendientes a justificar sus demandas y sus intereses y que se traducen en paradigmas historiográficos ${ }^{1}$ que dan sentido a la identidad, la cultura y el vínculo con la tierra de su población.

${ }^{1}$ Según Thomas Kuhn (2004, 13-33), los paradigmas pueden entenderse como "realizaciones científicas universalmente reconocidas que, durante cierto tiempo, proporcionan modelos de problemas y soluciones a una comunidad científica”. En este sentido, los paradigmas pueden atraer en torno a sí "a un grupo duradero de partidarios, alejándolos de los aspectos de competencia de la actividad cientifica”. No obstante, el principal problema del uso de paradigmas en la construcción de narraciones históricas radica en que pueden condicionar todo el proceso de investigación, al punto de afectar la formulación de conclusiones acerca del fenómeno estudiado, puesto que inducen al historiador a seleccionar los resultados más relevantes o convenientes para confirmar su paradigma, dinámica en la que se privilegian ciertas narraciones y se consideran irrelevantes otras. 
Algunos rastros de estos mitos fundacionales que buscan congregar en torno a sí la identidad colectiva de los israelíes están presentes en las distintas interpretaciones de la historiografía israelí acerca de los diferentes momentos que ha atravesado el conflicto con Palestina. En cada una de estas interpretaciones, los escritores israelíes han intentado resaltar su identidad y justificar sus acciones, sus derechos y su existencia como comunidad diferenciada, todo esto con el objetivo de defender su vínculo con un territorio que aún hoy se encuentra en disputa. Con el fin de explicar este proceso de historización, se hará un recuento de las principales corrientes historiográficas que han definido la conciencia colectiva de Israel, con énfasis en las discusiones que estas narrativas plantearon a su sociedad en distintos momentos del surgimiento y la evolución del pensamiento nacionalista, encargado de justificar la existencia de Israel en la región de Medio Oriente y de regular su relación con el otro.

\section{Orígenes y desarrollo del pensamiento nacionalista judío}

Es importante resaltar que el proceso que llevó a la creación de los mitos fundacionales israelíes estuvo enmarcado por un contexto histórico de grandes cambios a finales del siglo XIX, cuando el nacionalismo europeo y la formación de los Estados nacionales favorecieron la homogenización de los países, en una dinámica que culminó con la persecución de múltiples minorías dentro de los nuevos Estados europeos. Esta situación derivó en el brote de un sentimiento antijudío por toda Europa que ocasionó la migración de judíos europeos hacia Palestina (la mayoría de origen askenazi), en vista de la sistemática exclusión y persecución que sufrían en estos territorios. Tal como subraya Neuberger (1999): "Si bien el sionismo es la expresión del vínculo histórico que relaciona al pueblo judío con la Tierra de Israel, el sionismo moderno podría no haber surgido como movimiento nacional activo en el siglo XIX sin 
la aparición del antisemitismo de la época, al que precedieron siglos de persecución".

Fue en este contexto que nació el sionismo como movimiento que buscaba una solución definitiva a la cuestión judía en Europa, debido al fracaso de otras corrientes de la Ilustración judía ${ }^{2}$ que intentaban avanzar hacia una total integración de los judíos en las sociedades europeas. El sionismo se alimentó de ideas protosionistas como las planteadas por los rabinos Zvi Hirsch Kalischer y Yehuda Hay Alkalay, ${ }^{3}$ quienes sugirieron que la redención de los judíos podría darse de manera natural al producirse una vuelta de su población a la Tierra de Israel. ${ }^{4}$ Del mismo modo, autores como el filósofo Moisés Hess en su libro Rome and Jerusalem. A Study in Jewish Nationalism, publicado en 1862, pusieron sobre la mesa discusiones bastante revolucionarias para su época, en este caso en la forma de 12

${ }^{2}$ Fueron varias las opciones planteadas para afrontar la discriminación sufrida por los judíos en Europa. Las más relevantes fueron: propiciar migraciones masivas al continente americano, generar procesos de integración a las comunidades nacionales emergentes (asimilación), construir enclaves religiosos con altos niveles de autonomía, articular el judaísmo a los movimientos revolucionarios de corte socialista y consolidar un Estado que aglutinara a toda la población judía dispersa en la diáspora (en esta opción, los judíos serían considerados un pueblo con un carácter nacional diferenciado, no sólo en términos religiosos).

${ }^{3}$ Yehuda Hay Alkalay escribió en 1865 el texto titulado Raglei Mevasser, donde planteó que la redención tendría que ser construida por el pueblo y no a través de un Mesías encargado de realizar milagros como en los días del éxodo de Egipto (Alkalay 1985). Este enfoque revolucionario lo enemistaría con las corrientes ortodoxas al plantear un judaísmo de acción que no dependía del mesianismo y la impotencia aprendida (Silber 2008, 120-121). Por otro lado, Zvi Hirsch Kalischer (1964), en su libro Drishat Zion, publicado por primera vez en 1862, hizo un llamado para que los judíos siguieran el ejemplo de los italianos y los húngaros en su camino a la regeneración nacional, e hizo un énfasis especial en la creación de asentamientos agrícolas en Tierra Santa con el fin de lograr la Redención (Lewis n.d.).

${ }^{4} \mathrm{La}$ Tierra de Israel es un término histórico empleado en la tradición judía y cristiana para referirse a los antiguos reinos de Judá e Israel. Sin embargo, en principio, dentro del pensamiento judío este concepto no hacía ninguna referencia a reivindicaciones políticas tendientes a reclamar fronteras territoriales. Aun así, llegado el siglo XIX, adquirió un significado más político de la mano del sionismo, y se convirtió progresivamente en un concepto geopolítico que marcaba el lugar donde se deseaba consolidar la construcción de un Estado soberano para el pueblo judío. 
cartas donde hacía paralelismos entre la Reunificación Italiana de 1861 y una posible reunificación del pueblo judío. En sus palabras, "el renacimiento de Italia (como nación) anuncia la resurrección de Judah” (Hess 1918, 86) y la unidad nacional del pueblo judío, postura que lo llevó a ser especialmente crítico con la corriente reformista alemana que negaba el carácter nacional del judaísmo.

Ahora bien, la mayoría de los historiadores del sionismo coinciden en que la primera manifestación política de la idea de una unión del pueblo judío en términos similares al nacionalismo europeo del siglo XIX (Morocutti 2015, 76) ocurrió en Rusia y Ucrania con la organización de judíos rusos en la llamada Hoveve Tzion (Amantes de Sion), la cual se articuló como respuesta a la judeofobia creciente en la Rusia zarista luego del asesinato de Alejandro II en 1881 y el surgimiento de los pogromos como forma de aislamiento y pauperización de la vida judía. Este grupo, formado por intelectuales en principio influidos por ideas ilustradas y cosmopolitas, terminó por aceptar el principio de autoemancipación hebrea en vista de la constante exclusión y marginación que experimentaban los judíos en Rusia. En términos generales, la autoemancipación se alimentaba de las premisas del nacionalismo orgánico ruso y su objetivo era consolidar una identidad colectiva capaz de aglutinar a toda la comunidad hebrea de Europa del Este (76).

A pesar de que a lo largo del siglo XIX se instauró una tendencia a concebir a los judíos no sólo como parte de una comunidad religiosa, sino también como miembros de una comunidad particular más o menos homogénea dispersa por toda Europa, habría que esperar hasta 1897 para que se hablara seriamente de un proyecto de Estado-nación judío. El factor determinante para que esto sucediera fue el Primer Congreso Sionista celebrado en Suiza en 1897. En este evento, el considerado fundador del sionismo político, Theodor Herzl, impulsó formalmente la idea de un sionismo político dirigido a crear un Estado judío capaz de brindar protección a esta población 
ante el embate histórico del antisemitismo que periódicamente surgía en Europa. ${ }^{5}$ Ahora bien, esto no quiere decir que antes de este suceso no se hubiera pensado la historia judía desde una perspectiva integradora. Historiadores como Heinrich Graetz dedicaron su trabajo a repensar la historia judía en obras destacadas como History of the Jeres (1876), que inauguró una corriente historiográfica cuyo argumento era que los judíos constituían un pueblo con una historia continua que los aglutinaba como nación (Graetz 1891).

Graetz es señalado por los historiadores israelíes como uno de los primeros en plantear las bases de una conciencia histórica judía precisamente con su obra History of the Jews, escrita entre 1852 y 1876, al asentar los argumentos necesarios para establecer una autoconciencia renovada que posibilitó más tarde articular un movimiento político judío mundial a través del sionismo en su vertiente política. A pesar de que esta obra no puede ser entendida como una historia de la nación judía en toda regla, sí constituyó un primer esfuerzo por resaltar la estabilidad del estilo de vida judío por sobre cualquier cambio abrupto o influencia externa. Esta novedosa concepción de la historia judía sirvió para rastrear el lugar del pueblo judío en la historia mundial, lo que despertó el interés por los estudios judíos en idioma alemán, al tiempo que se impulsó una corriente historiográfica que buscaba conectar la historia judía con la sociedad europea moderna (Gelber 2011, 101).

Este interés por la historia judía no se limitó a obras escritas en alemán, sino que, paralelamente, se multiplicaron los esfuerzos por generar textos en yiddish y en hebreo. Dicho renacer lingüístico permitió el surgimiento de proyectos como Hochmat Israel (Gelber 2011, 101), pertenecientes al movimiento de la Ilustración judía, los cuales fueron vitales

${ }^{5}$ No obstante, este primer movimiento político sionista no poseía un carácter palestinocentrista y estaba dispuesto a considerar otros lugares, como Uganda, Argentina o Siberia, entre otros. El palestinocentrismo sólo se consolidó tras la Declaración Balfour de 1917. 
para popularizar la idea de Jojmat Israel, ${ }^{6}$ fuertemente ligada al despertar cultural-nacional de los pueblos que se encontraban sometidos por los grandes imperios multinacionales europeos. La diferencia entre esta interpretación de la historia y otras vertientes del pensamiento judío del siglo XIX era su especial énfasis en "remodelar la identidad judía a nivel nacional”. El mayor exponente de esta tendencia historiográfica fue Peretz Smolenskin, quien editó y colaboró en la revista hebrea Hashachar, publicada periódicamente en Viena entre 1842 y 1885 , donde recalcó la existencia social de los judíos como una nación y no como parte asimilada de las naciones en las que habían nacido (Gelber 2011, 102).

La historiografía judía del siglo XIX puede entenderse, según David Myers, como un fenómeno híbrido que se debatía entre dos paradigmas en principio difícilmente reconciliables: i) el deseo de producir una historia ligada a los principios de la autorrepresentación judía, y ii) la respuesta al riguroso espíritu científico alemán. Esta discusión, en última instancia, desembocó en la necesidad de elegir entre destacar en mayor o menor medida la herencia y la cohesión judía, o priorizar el objetivo de que los judíos fueran aceptados y asimilados en las sociedades europeas (Myers y Ruderman 1998, 92-93). El surgimiento de esta dicotomía se explica porque, para el siglo xIx, la religión seguía siendo el foco de la identidad judía en Alemania, lo que llevó a que los primeros historiadores judíos se preocuparan primordialmente por estudiar textos religiosos judíos, por medio de una historia de carácter apologético que enfatizaba los aspectos racionales de la religión judía, en un intento por repensar o ignorar las dimensiones místicas de estos textos. De fondo, el estudio histórico del judaísmo obedeció en

${ }^{6}$ Jojmat Israel fue un movimiento académico que buscaba entender el judaísmo desde una perspectiva científica (Krell 2014, 77). En términos generales, era un movimiento multidisciplinar que resaltaba la búsqueda del conocimiento con el fin de alcanzar una identidad judía colectiva, la cual tendría que ser útil para el presente y el futuro de la comunidad. 
este periodo a la necesidad de responder preguntas sobre qué eran los judíos, su cultura y su sociedad, y hacia dónde debía avanzar esa comunidad. Para contestar estos cuestionamientos, autores como Heinrich Graetz optaron por pensar el judaísmo en términos nacionales y no sólo religiosos.

Llegado el siglo xx, el modelo explicativo de la historia judía como una historia nacional sería desarrollado de forma más completa por historiadores como Simón Dubnow (1939), quien a pesar de no ser afín a los preceptos sionistas y ser un crítico de la idea de movilizar a las masas judías hacia Palestina, centró sus esfuerzos en resaltar el logro de las poblaciones judías al mantener altos niveles de autonomía cultural, social y política dentro de las comunidades en que se desenvolvían (78). La escritura de la historia judía de este periodo estuvo íntimamente influida por el éxito político del sionismo tras la Declaración Balfour de 1917 y por los logros obtenidos por la delegación sionista tras la Conferencia de Paz de Versalles, los cuales pusieron al movimiento sionista en el mapa de las relaciones internacionales al dotarlo de una vitalidad histórica antes casi inexistente. En este sentido, con el apoyo británico a la construcción de una patria judía en Palestina, la historia judía se abocó a probar la viabilidad del proyecto sionista y, por tanto, a reconceptualizar el territorio y los asentamientos judíos en él, adaptando su interpretación en función de los intereses nacionalistas del sionismo.

El principal paradigma historiográfico que se instaló en esta segunda generación de historiadores fue la creencia de que Palestina era una tierra vacía que esperaba ser redimida por el pueblo judío. Según este relato, desde 1800 Palestina se había convertido en un desierto improductivo debido a la mala administración otomana, que gobernaba a la distancia unas tierras yermas cultivadas por agricultores ajenos a la región. Esta visión se complementó con la premisa de que en Palestina vivía ya, para entonces, un número considerable de judíos que se encontraban asfixiados por los proyectos de cultivo intensivo otomanos, los cuales impedían que la tierra tuviera fertilidad al 
convertirla en un espacio estéril, deforestado y desértico (Ramos 2014, 4-5).

Esta interpretación acerca de la historia demográfica de la región sentó las bases para argumentar que siempre hubo una significativa presencia judía en Palestina durante los 2000 años de ausencia de un Estado judío en la zona, y que este territorio estuvo, presuntamente, poco poblado hasta la primera ola migratoria judía en 1880 (Dershowitz 2003, 15). En consecuencia, Ben-Zion Dinur y otros historiadores se encargaron de establecer una conexión histórica que iba desde la destrucción del Templo de Jerusalén hasta el periodo moderno, y que defendía una continuidad de la presencia judía en la Tierra de Israel en la forma de fuertes comunidades que se reforzaron con la llegada de nuevos inmigrantes. ${ }^{7}$ Por su parte, la presencia de los árabes se interpretó como el producto de una conquista de la tierra ocurrida en el 634 e.c., tras la cual éstos habían permanecido en calidad de ocupantes extranjeros, a diferencia de las poblaciones judías, que en teoría se habían mantenido fieles a sus tradiciones y en conexión con su patria pese a que quedaran relegadas a espacios reducidos dentro de ella.

Estos mitos fundacionales retomarían la célebre frase acuñada por la delegación sionista que acudió a los diálogos precedentes a la firma del Tratado de Versalles, "Una tierra sin pueblo, para un pueblo sin tierra", y que a principios del siglo xx hizo famosa el periodista británico de origen judío Israel Zangwill (Sánchez 2010) cuando recurrió a ella constantemente

${ }^{7}$ El problema de esta afirmación es la poca información empírica con la que se cuenta para comprobar su validez. Cualquier consideración acerca de la composición demográfica de Palestina es comúnmente rechazada debido a la poca confiabilidad de los datos arrojados por los censos llevados a cabo por el Imperio otomano. Así, algunas de las críticas más habituales es que éstos no contabilizaban a "los residentes extranjeros [...] los residentes ilegales hicieron todo lo posible para evadir el censo, al igual que las personas que deseaban evadir el servicio militar y los impuestos”. Del mismo modo, aunque los censos poblacionales efectuados por el Mandato británico poseían un mayor grado de credibilidad, no se publicó ninguno después de 1931, lo que deja incompleto cualquier análisis escrupuloso sobre la demografía palestina (MidEast Web 2017). 
para vincular las reclamaciones de tierra sionista en Palestina con el argumento de una virtual inexistencia de población en la zona. ${ }^{8}$ Por otro lado, una segunda parte del discurso defendía que el verdadero motivo por el cual la población árabe había aumentado en Palestina estaba ligado a la inmigración que había estimulado los avances consolidados por los judíos en materia de infraestructura, productividad y riqueza, lo que creaba un giro explicativo que negaba la presencia de una comunidad autóctona considerable.

En pocas palabras, con esto se quería argumentar que, desde 1887, la redención del país impulsada por los Amantes de Sion $^{9}$ no se configuraba como un proceso de conquista, sino de compra legítima de tierra con el fin de redimirla a través del trabajo de los pioneros ${ }^{10}$ que, con su esfuerzo, la volvían productiva. En estas ideas influyó el populismo romántico ruso, que abogaba por la redención del agricultor esclavizado, pero ubicando la tierra en el centro del proceso. Ahora bien, esta concepción de la tierra y su redención a través del trabajo judío conllevó el abandono progresivo, desde 1905, de los modelos de asentamientos cooperativos de tipo moshav, dependientes de empresas filantrópicas al estilo de los impulsados por Ed-

${ }^{8}$ Zangwill declaró en varias ocasiones: "Palestina no tiene más que una pequeña población de árabes y fellabin [campesinos, en árabe] y unas errantes y chantajistas tribus de beduinos sin ley [...] Restauren el país sin pueblo al pueblo sin país. Tenemos algo que ofrecer, así como algo que conseguir. Podemos barrer al chantajista - sea pasha o beduino-y hacer que el desierto florezca como una rosa, además de construir en el corazón del mundo una civilización que puede ser mediadora e intérprete entre Oriente y Occidente” (Ramos 2014, 5).

${ }^{9}$ Los Amantes de Sion fue un movimiento popular, social y nacional judío vigente entre finales del siglo XIX y principios del Xx. Su principal objetivo era propiciar la renovación del pueblo judío mediante su retorno a Sion (la Tierra de Israel), donde se planteaban construir una sociedad judía viable, de carácter nacional, aunque no necesariamente estatal.

${ }^{10}$ El término pionero remite a la primera ola de inmigrantes judíos llegados a Palestina durante la primera aliyá, ocurrida entre 1812 y 1903 , y que huían de la persecución que sufrían en Europa (en especial provenientes del Imperio ruso). Su principal característica fue la creación de comunidades agrícolas con un fuerte carácter judío que intentaba reconstruir una sociedad viable en la Siria otomana. 
mond de Rothschild, en pos del privilegio de los asentamientos con un fuerte carácter etnocomunal llamados kibutz. ${ }^{11}$ Estos últimos buscaban emplear principalmente mano de obra judía en detrimento de la más económica mano de obra árabe, puesto que establecieron una relación intrínseca entre el resurgimiento de la nación judía y la conquista del trabajo.

En este sentido, la 'Tierra de Israel' pasó de ser un concepto teológico a uno geonacional que fue remplazando rápidamente el término 'Palestina' arraigado en la tradición europea. Con ello se instaló una plataforma dirigida a consolidar progresivamente una memoria etnocéntrica, enfocada a la hebreización de la región por medio de la modificación de los nombres de los entornos urbanos, rurales y naturales, que ahora se integraban a la visión nacional del Estado y la sociedad judía prenacional y, más tarde, nacional (Benvenisti 2000, 14). Dicho proceso se vio reforzado por la visión que los primeros historiadores israelíes tenían de la población local, entendida como un conjunto de árabes o tribus de beduinos separadas entre sí, los cuales carecían primordialmente de cualquier

${ }^{11}$ La diferencia entre kibutz y moshav radica principalmente en los principios ideológicos fundacionales que dieron forma a sus modelos de colonización. En este sentido, pese a que ambos se fundamentan en la doctrina sionista y el "ideal bíblico del trabajo agrícola como actividad vital del hombre y como instrumento de arraigo al espacio", organizan de manera diametralmente distinta sus asentamientos. Así, los kibutz herederos de una colonización colectiva encabezada por la segunda aliyá (1904 y 1913), mayormente compuesta por “jóvenes trabajadores rusos” formados en la conciencia política y social del socialismo marxista y el anarquismo, tenían como objetivo establecer una sociedad completamente nueva, mucho más justa e igualitaria, que se regiría por comunidades agrarias progresistas estrictamente basadas en la igualdad social, el principio de la ayuda mutua y la propiedad colectiva de la tierra. En contraposición, el moshav surgió de los colonos judíos que llegaron a Palestina durante la primera aliyá en 1880 y fundaron colonias de propietarios independientes que fueron acentuando su preferencia por el respeto de una mayor capacidad de acción y libertad individual, junto al incentivo de la iniciativa privada. A su vez, en las comunidades colectivas o kibutz, el trabajo y los beneficios de éste se reparten equitativamente, mientras que en los pueblos cooperativos o moshav, las granjas individuales y las casas se trabajan de forma independiente, pese a que posteriormente la producción se pone en un fondo común y se comercializa de forma colectiva (Poblete y Pardo 1989, 206). 
derecho legítimo sobre la tierra al estar desprovistos de una identidad nacional particular (Ramos 2014, 6).

Ahora bien, pese a lo que pueda parecer, los historiadores y los políticos sionistas no usaban la frase "Una tierra sin pueblo" de manera literal. En realidad, más allá de querer probar la inexistencia de población autóctona en la zona (lo cual resultaba imposible dada la presencia británica en Palestina durante su Mandato), se pretendía resaltar que no había ningún pueblo con conciencia nacional en Palestina. La razón para insistir en este punto radicaba en que, al señalar que ninguno de los habitantes árabes de Palestina cumplía con las características de los movimientos nacionalistas europeos, el proyecto de una nación judía moderna en la Tierra de Israel sería un resultado lógico acorde con el desarrollo histórico occidental.

Hay que recordar que, para entonces, las poblaciones dentro de territorios objeto de colonización eran consideradas mayoritariamente nómadas, tribus, bárbaros y, en general, primitivas, en una dinámica que restringía su derecho sobre la tierra al no poder apelar a una entidad cultural de tipo nacional que se adjudicara su dominio político. En resumen, al no poseer una ideología nacionalista o un Estado propio, las poblaciones autóctonas carecían de una organización social y política que validara su derecho sobre la tierra desde la perspectiva occidental (Benvenisti 2000, 7). Aunado a esto, el que la historiografía sionista remarcara constantemente que Palestina había sido convertida en un terreno yermo y desolado por los árabes, vinculó la construcción de un Estado-nación judío a la llegada de la modernización a Medio Oriente. Dicho proceso terminó por dar una dimensión y una justificación moral de carácter universal a la presencia judía en la Tierra de Israel, lo que le permitió obtener el apoyo de diversas personalidades importantes en Europa y Estados Unidos.

Por otro lado, con la creación del Departamento de Historia Judía de la Universidad Hebrea de Jerusalén, de la mano de académicos como Itzhak Baer y Ben-Zion Dinur, educados 
en el historicismo ${ }^{12}$ por estudiosos como Friedrich Meinecke y Eugene Taubler, se comenzó una carrera por resolver las tensiones entre el carácter científico de la historia y las necesidades del nacionalismo sionista. Tal vez la contribución más importante de la escuela de Jerusalén durante su apogeo en la década de 1930, influida profundamente por el romanticismo nacionalista europeo de la segunda mitad del siglo XIX, fue la creación de tres principios fundamentales que marcarían la historiografía sionista moderna: una continuidad en el modus vivendi judío a lo largo de los siglos, características económicas y sociales típicas de la diáspora judía, y una cultura judía coherente (Gelber 2011, 50-51). El énfasis de sus trabajos consistió en dejar atrás el tratamiento de los problemas históricos a través del judaísmo como religión, en pos de una interpretación que privilegiaba el judaísmo como nacionalidad. Para ello, enfocaron sus esfuerzos en tratar temas relacionados con la soberanía, la autonomía judía y las explicaciones políticas a fenómenos que hasta el momento eran considerados de orden religioso o comunal (104).

Con esto en mente, Itzhak Baer y Ben-Zion Dinur crearon en 1935 el Journal of Zion, con la esperanza de que se convirtiera en una plataforma común para los estudiosos de la historia judía. El objetivo de la publicación era escribir una historia nacional que resaltara la continuidad y la unidad interna de la historia judía y se ubicara por "encima del tiempo (periodos históricos) y el espacio (la dispersión judía en el exilio)" (Gelber 2011, 105). En última instancia, la meta era enfatizar

${ }^{12}$ El historicismo nació en 1839 de la mano de liberales románticos alemanes como Rudolf Haym, pero más tarde lo retomarían los historiadores conservadores. $\mathrm{Su}$ objetivo principal era argumentar que los hechos individuales deben entenderse en el contexto de un desarrollo histórico universal más amplio. Además, el historicismo explica los acontecimientos de la historia mediante conceptos fundamentales, como el desarrollo del Estado moderno y la libertad. Estas características permitieron que el historicismo se convirtiera en un principio vital para estudiar la formación del nacionalismo alemán durante el siglo XIX, y sirvieron además para que historiadores como Leopold von Ranke analizaran el surgimiento de los Estados modernos del siglo XVI europeo (Alemania, Inglaterra y Prusia) (Liebel 1971, 380-381). 
los elementos que acercaban a los judíos y al mismo tiempo minimizar la relevancia de las historias locales de los diferentes países de procedencia de los inmigrantes judíos. Este cambio en la manera de hacer la historia se debió a que los nuevos historiadores prestaron mayor atención al estudio de las masas judías, y se alejaron de las investigaciones históricas anteriores, mayormente centradas en las élites eruditas rabínicas (tal como pasó con los textos de Graetz y otros historiadores de la generación anterior).

Paralelamente, en las décadas de 1920 y 1930 surgieron historias acerca del movimiento sionista producidas por historiadores amateurs, en su mayoría activistas, que se encargaron de registrar los primeros relatos acerca del surgimiento, el desarrollo y los principales esbozos del movimiento, en un intento de otorgarle coherencia y legitimidad. Autores como Nahum Sokolow (1919), Adolf Bohm (1920) y Yizhak Gruenbaum (1946) se encargaron de escribir historias completas del sionismo que alimentaron los trabajos de estudiosos como Richard Lichtheim (1951), considerado el primer historiador sionista alemán. Esta dinámica permitió que poco a poco los paradigmas historiográficos del sionismo ganaran legitimidad en las distintas comunidades judías, lo que contribuyó a que se alcanzara el reconocimiento nacional judío a nivel interno e internacional. Desde entonces, el principal objetivo de la primera ola de historiadores sionistas fue consolidar la legitimidad de estos paradigmas.

Arraigada la idea de crear un Estado en la Tierra de Israel, se incentivó la escritura de una historia reivindicativa ${ }^{13}$ ligada a la necesidad de remarcar las particularidades étnicas, lingüísticas, mitológicas y simbólicas que aglomerarían a la nación judía, todo esto en un intento de trascender el tono conmovedor con

${ }^{13}$ Las obras apologéticas tienen por objetivo defender la religión, así como sus prácticas y sus creencias, por medio de textos dirigidos tanto a autoridades políticas preeminentes como a la opinión pública en general. Todo aquello busca influir en las interpretaciones que la sociedad hace de la historia y la vida cotidiana (Torres 2009, 272). 
el que habían sido escritas las primeras historias judías a fin de atraer el apoyo internacional, pues la prioridad era justificar e impulsar la llegada de inmigrantes a Palestina. Esto desembocó en una interpretación renovada de la diáspora, la empresa sionista en la formación del yishuv ${ }^{14}$ y la cristalización de los objetivos sionistas en Palestina, ahora transversalizados por la idea de una posible estatalidad.

Libros pioneros escritos por Kurt Nawratzky (Die Jüdische Kolonisation Palästinas, 1914), Arthur Ruppin (Ha-Hityashout Ha-Hakla'it shel Ha-Histadrut Ha-Tziyonit be-Eretz Yisrael, 1908-1924, 1925) y Alexander Bein (Toldot Habityashvut ha-Tziyonit, 1942), acerca de la colonización agrícola sionista en Palestina, tenían como meta convencer al lector de las bondades de establecerse en Palestina dada su viabilidad productiva, económica, social y política. Ahora el proyecto de asentamiento judío en Palestina era presentado como autosuficiente y totalmente capaz de satisfacer las necesidades del pueblo judío. En términos generales, estas obras tenían por objetivo disipar cualquier duda entre judíos y no judíos, en torno a las perspectivas materiales del sionismo en Medio Oriente (Gelber 2007, 51).

\section{Segunda Guerra Mundial y evolución de la historiografía israelí}

Más tarde, con la Segunda Guerra Mundial y la materialización de la estatalidad tras la creación de Israel en 1948, la historiografía sionista cambió por completo su objetivo al encontrarse en una situación privilegiada en comparación con las demás

${ }^{14}$ El término yishuv es usado en dos sentidos distintos por la historiografía israelí. En primera instancia, se habla del Antiguo Yishuv para referirse a los judíos que habitaban en la Siria otomana antes de 1882, momento en que ocurre la primera aliyá. Por otra parte, tras 1882 se usa el concepto Nuevo Yishuv para referir a los inmigrantes judíos que se asentaron en la zona entre la primera aliyá y la consolidación del Estado de Israel en 1948 (Pérez y Sánchez 2012, 40). 
alternativas que tradicionalmente se habían planteado para tratar la cuestión judía en Europa (asimilación, bundismo y ortodoxia religiosa). El factor principal que permitió esta dinámica fueron las abrumadoras consecuencias del Holocausto en las comunidades judías de Europa, que al final de la guerra lo habían perdido casi todo, después de un proceso de persecución y exterminio que dejó aproximadamente cinco millones de judíos asesinados. En consecuencia, en virtud de un acontecimiento de tales dimensiones y dada la experiencia histórica del antisemitismo europeo, muchas personas se convencieron de que la construcción de un Estado propio para los judíos era la única solución posible para evitar un suceso similar.

Este cambio en el panorama internacional facilitó la acción de organizaciones internacionales como la Agencia Judía, y de grupos paramilitares como la Haganá y el Irgún, los cuales lograron establecer un Estado judío relativamente estable en la Tierra de Israel luego de una guerra de tres años. Este hecho disipó las dudas acerca de la posibilidad material del proyecto sionista de resistir la hostilidad árabe y sortear los obstáculos puestos por el Mandato británico (Gelber 2007, 53), y creó un escenario que reforzó las tesis originales del sionismo en torno a la necesidad de impulsar la migración judía a la Tierra de Israel.

Este cambio en el contexto internacional y local hizo que la historiografía sionista cambiara su enfoque de una autojustificación matizada por la necesidad de convencer a las potencias europeas, a un esfuerzo constante por sentar las bases para la consolidación del Estado y la identidad de la sociedad a través de la reafirmación de los paradigmas historiográficos clásicos. Ahora su tarea principal era exaltar el papel de los participantes en la guerra de independencia, consolidar el vínculo de los judíos con la tierra y determinar el alcance territorial de la nación. Como resultado, muchos historiadores como Gelber y Ben-Zion Dinur trabajaron en recuperar y reforzar los intentos por trazar una línea ininterrumpida que atravesaba la Antigüedad, la Edad Media y la era moderna y que defendía la afiliación continua de la nación judía a la Tierra de Israel, 
lo que convirtió este vínculo en el núcleo de la historia judía moderna.

De este modo, en 1948 la historia del sionismo se transformó en la historia del Estado de Israel y determinó la interpretación de su crecimiento interno, sus relaciones internacionales, el vínculo con los judíos de la diáspora y la convivencia con sus vecinos árabes. Una de las consecuencias más importantes fue que la historiografía israelí se focalizó en rastrear las características comunes del sionismo y abandonó progresivamente el desarrollo de este movimiento en países particulares y de manera aislada. Para entonces, los temas más recurrentes en la historiografía sionista fueron la historia del yishuv durante la época otomana, el Mandato británico y los primeros años del Estado, el despertar de la conciencia nacional judía en la diáspora y la conversión de los experimentos de asentamiento judío en Palestina del siglo XIX en parte intrínseca de los logros sionistas.

La obra cúspide de esta segunda ola de historiadores sería Toldot Am Israel [Historia del pueblo judío], publicada en 1960 en tres volúmenes y traducida a múltiples idiomas. En ella se cristalizaron los esfuerzos de la escuela de Jerusalén, que, durante dos generaciones, se esforzó por convertir la historia judía en una historia nacional continua que incluía los sucesos ocurridos desde el Antiguo Testamento hasta el Estado moderno de Israel, siguiendo los preceptos de Baer, Dinur y el resto de los historiadores que participaron de esta escuela (Ben-Sasson 1969). Tal vez la mayor ausencia de esta segunda etapa de la historiografía israelí fue el análisis de las consecuencias de la creación del Estado de Israel, vacío que sería llenado más tarde por los llamados nuevos historiadores, como veremos más adelante.

No obstante, con el ingreso de las tesis sionistas a la Universidad Hebrea de Jerusalén y sus universidades hermanas en 1960, la historiografía sionista se enfrentó a una profunda crisis de la mano de un conjunto de historiadores que, si bien habían sido formados a la luz de los mitos fundacionales sionistas, po- 
nían en duda sus principios en función de las tendencias de la historiografía occidental y los métodos, los temas y los objetivos que planteaba. La escuela de los Annales y el relativismo de Edward H. Carr pusieron en entredicho la posibilidad de la historia sionista para ingresar, consolidarse y difundirse en la academia israelí (Gelber 2007, 56). Dicho dilema fue explicado de la siguiente manera por Israel Kolatt, pionero en la investigación y la enseñanza de la historia del yishuv, en su texto On the Research and Researcher of the History of the Yishuv and the Zionist Movement, escrito en 1970 y publicado en 1976 por la Universidad Hebrea de Jerusalén:

Este proyecto de descubrir el pasado enterrado bajo montones de estereotipos, imágenes, memorias, polémicas y fraseología es una gran empresa [...] Aún más difícil es la necesidad intelectual del erudito de superar los conceptos heredados, examinar sus prejuicios, experiencias, recuerdos, sentimientos y preferencias y considerar el objeto de investigación como un fenómeno histórico. La carga de la ideología sionista y la apologética ha convertido la reevaluación de la historia sionista en un proceso complejo y delicado (Kolatt 1976, 23).

El análisis de Kolatt tendría amplia resonancia en el futuro con la llegada del pospositivismo y de historiadores revisionistas ${ }^{15}$ producto de diversos factores que van desde el cambio de paradigmas en las ciencias sociales y el avance de la propaganda antisionista árabe, hasta el fortalecimiento de las ideas promulgadas por la nueva izquierda en Estados Unidos y Europa, entre otros elementos que rompieron el monopolio sionista de la historia de Israel e hicieron incompatibles las necesidades de corte nacionalista del sionismo con las exigencias de la historiografía moderna occidental. Además, con la aper-

${ }^{15}$ Los historiadores revisionistas son un grupo de académicos de la década de 1980 cuyos mayores representantes fueron Benny Morris, Tom Segev, Avi Shlaim, Ilan Pappé y Simha Flapan. Estos investigadores reevaluaron y criticaron la historia oficial de la fundación del Estado de Israel y de la guerra de 1948 con base en documentos de archivos israelíes, cisjordanos y occidentales desclasificados de forma masiva, los cuales les permitieron indagar en nuevas problemáticas y dar nuevas interpretaciones a multiplicidad de sucesos y fenómenos de la historia israelí (Gijón 2008, 28). 
tura de una gran cantidad de archivos de partidos políticos, kibutz y otros movimientos, organizaciones, instituciones e individuos (especialmente los Archivos Sionistas Centrales, los Archivos del Estado de Israel y los archivos de las Fuerzas de Defensa de Israel), la forma de estudiar la historia de Israel se diversificó y se ampliaron las interpretaciones y las conclusiones a las que llegaban los investigadores.

Tal vez el punto de inflexión que abrió paso a este tipo de historia fue la guerra de los Seis Días, ocurrida en 1967, evento que marcó un antes y un después en la historia ideológica, diplomática y política del asentamiento judío en Palestina, y derribó tabúes historiográficos imposibles de sobrepasar en 1950, como la actitud del sionismo hacia la situación de los judíos durante la Segunda Guerra Mundial, sus relaciones con el mundo árabe y la interpretación de Israel como una sociedad multicultural, multinacional y plurirreligiosa. Además, la guerra de los Seis Días cambió el carácter del conflicto al convertir a los egipcios-palestinos en la Franja de Gaza y a buena parte de los jordanos-palestinos (autóctonos y refugiados en Cisjordania) en población netamente palestina luego de que los territorios en que habitaban quedaran sin el control de potencias extranjeras árabes.

Esto implicó que todos aquellos palestinos que no quedaron en territorios anexados por Israel y no obtuvieron su ciudadanía, se convirtieron en un grupo nacional diferenciado de los árabes que reclamaban un Estado propio dentro del marco territorial que el Estado israelí concebía como suyo. En última instancia, esto transformó el conflicto de una confrontación árabe-israelí en un asunto entre palestinos e israelíes, lo que sirvió de antesala a la conformación de agrupaciones nacionalistas palestinas clandestinas que terminaron por crear la Organización para la Liberación de Palestina en 1964. En pocas palabras, ahora no se podía ignorar la identidad palestina pese al dominio territorial hegemónico que había logrado Israel al vencer a la coalición árabe y firmar la paz con Egipto, lo que dio espacio a nuevas temáticas en la historio- 
grafía israelí que se ocuparían de cuestionar los costos políticos y humanos de mantener los territorios ocupados por Israel tras la guerra.

Ahora bien, en la década de 1980 el mundo académico comenzó a vivir una transformación total en cuanto al enfoque usado para analizar el conflicto árabe-israelí. A partir de entonces se prestó una atención significativa a los costos y los fracasos que implicó la creación del Estado de Israel, y en muchas ocasiones se relegó a un segundo plano el estudio de sus logros. Numerosos historiadores y sociólogos revisionistas optaron por cuestionar tres puntos básicos de la historia ideológica y política sionista: "su actitud hacia los árabes, el Holocausto y los inmigrantes llegados en los primeros tiempos del Estado" (Gelber 2007, 64). La consecuencia directa de este giro en la interpretación de la historiografía israelí fue la división de su historia en torno a la explicación de tres ejes articuladores: "Israel y sus alrededores, Israel y el pueblo judío, e Israel y los ciudadanos que presuntamente recibieron un trato injusto" (65). El interés por estos temas se ha renovado constantemente en vista de que ninguno de los problemas que surgieron tras 1948 ha tenido una solución definitiva.

Surgió entonces un grupo de estudiosos que centró el eje de sus investigaciones en el conflicto palestino-israelí y se enfocó en describir la opresión y las violaciones de los derechos que los palestinos habrían sufrido a manos de Israel. A estos investigadores se les denominó los 'nuevos historiadores', debido a sus intentos de reinterpretar los acontecimientos ocurridos durante la guerra de independencia de 1948 resaltando las consecuencias humanas y el efecto en la consolidación de la sociedad y el Estado israelí. Académicos como Ilan Pappé, Avi Shlaim y Norman Finkelstein se han preocupado por deconstruir los principales mitos historiográficos de la historia israelí con extensas críticas acerca de su objetividad y sus conclusiones, lo que ha llevado a esta corriente a interpretar la historiografía sionista como un elemento de "alistamiento en la lucha política (sionista) como una de las fuerzas auxiliares 
en la toma del país", al tiempo que presenta a los historiadores sionistas como "autoridades y articuladores del espíritu de la nación” completamente influidos por principios ideológicos vinculados a un proceso de ingeniería social que, en palabras de Gabriel Piterberg, los asemejaba a "sacerdotes culturales" (Gelber 2011, 110).

En este sentido, historiadores como Shlomo Sand han centrado su trabajo en deconstruir la mayoría de los mitos nacionales israelíes y criticar su emplazamiento como paradigmas científicos. Así, examina la idea de que los judíos constituyeran una nación étnica inmutable que vivía en el exilio político desde hace 2000 años y cuyo principal objetivo era volver a su tierra natal, y argumenta que tal conclusión no tiene parangón en la historia de ninguna otra religión del mundo. En su libro La invención de la Tierra de Israel, Sand (2013) rastrea el origen étnico-biológico de la población judía moderna en los descendientes de conversos paganos en el norte de África, Yemen y el reino de los jázaros en la cuenca del Volga, lo cual, según el autor, es una prueba palpable de que el argumento de una nación étnicamente pura no puede sostenerse, razón por la cual, aparentemente, el sionismo no estaría en condiciones de sustentar derechos históricos o de procedencia sobre Palestina.

Por su parte, en el artículo "Zionism as Colonialism: A Comparative View of Diluted Colonialism in Asia and Africa", Ilan Pappé (2008) explica que uno de los grandes problemas que impulsaron los estudios de la historiografía profesional moderna giró alrededor de la idea de dotar de una explicación o una justificación a los grandes traslados poblacionales desde Europa hacia los otros continentes. Pappé parte de esta afirmación para explicar las preocupaciones de la historiografía sionista, cuya principal característica sería, para el autor, la combinación de un pensamiento de orden nacionalista con una práctica netamente colonialista. En sus palabras, esta dinámica convierte el proyecto sionista en Palestina en un tipo de colonialismo no convencional cubierto por diferentes mantos ideológi- 
cos, como el socialismo y las experiencias de comunitarismo (911).

Según Pappé (2008), el que los sionistas impulsaran sus enormes movimientos migratorios hacia Palestina a finales de un periodo marcado por el dominio europeo sobre grandes partes de Medio Oriente y otros lugares del mundo en nombre del progreso, dependiendo además de la protección de una metrópolis europea (aun cuando no fueran patrocinados por ésta) para continuar con su campaña colonizadora, es una clara muestra de un proceso colonialista que si bien resulta atípico, es innegable. En este sentido, para Pappé la llegada del sionismo a Palestina "sucedió en un siglo en que los colonos franceses colonizaban Argelia alegando un vínculo atávico y emocional con el suelo argelino no menos profundo que el que profesaban los primeros sionistas respecto a Eretz Israel” (912).

En general, la historiografía de los nuevos historiadores, sociólogos y geógrafos ha desviado su atención del análisis de la sociedad israelí dominante para centrarse en los grupos periféricos, en una dinámica que intenta rastrear la responsabilidad del núcleo duro de la política de Israel y del sionismo, alrededor de crímenes supuestamente deliberados contra las minorías palestinas y la población árabe de países vecinos. Han ampliado estos análisis, además, al trato de ciertos grupos judíos, como los sefardíes o los judíos etíopes. Por último, se han enfocado especialmente en el papel del militarismo israelí y su visión acerca del mundo árabe como un enemigo omnipresente, y han estudiado sus efectos sobre la configuración actual de la sociedad israelí.

\section{Conclusiones}

La importancia de analizar el desarrollo del conflicto palestinoisraelí a la luz de la historiografía israelí radica en que se puede examinar el problema más allá del supuesto de un enfrentamiento ancestral y religioso entre árabes palestinos y judíos, lo que 
permite rastrear los orígenes reales del conflicto, así como las herramientas discursivas de Israel para justificar su presencia en Medio Oriente. De esta manera, el análisis del conflicto puede alejarse de las posiciones más radicales y esencialistas, $\mathrm{y}$ enfocarse en el proceso de construcción de la identidad israelí a mediados del siglo XX.

No obstante, aún quedan por estudiar de manera más profunda diferentes periodos de la historiografía israelí, como las décadas de 1948-1958 y 1958-1978, debido a que buena parte de la historia escrita en estas etapas dependió casi en su totalidad de los testimonios de exmilitares y exfuncionarios israelíes, con objetivos políticos e ideológicos muy específicos que terminaron por influir en los relatos y las interpretaciones.

Empero, esto puede generar un enorme problema en la medida en que el desacuerdo académico vital para generar avances en el estudio se quede enquistado en una disputa meramente ideológica entre sionistas y no sionistas que elimine cualquier rastro de una base disciplinaria y un lenguaje común al abordar la historiografía israelí. La mayor dificultad de las investigaciones dedicadas a la revisión de los relatos históricos que se instalaron en la academia israelí en décadas pasadas es que terminen por centrarse únicamente en la defensa de preceptos sionistas o antisionistas y releguen a un segundo plano la discusión académica de los problemas actuales de la sociedad israelí y su necesidad de establecer diálogos diferentes con la población palestina y sus vecinos árabes.

Por otro lado, el estudio de cómo se construyó la identidad israelí cobrará importancia en los próximos años en vista de los cambios que se están perfilando en el conflicto palestinoisraelí. Cuestiones como el proyecto de anexión de amplias zonas de Cisjordania, legislaciones como la Ley del Estadonación y el progresivo desmantelamiento de la solución de los dos Estados, inevitablemente enfrentarán a Israel con la necesidad de repensar sus mitos fundacionales y sus construcciones culturales, ideológicas e identitarias, frente a la posibilidad de 
aplicar una solución de un solo Estado de carácter multinacional y plurirreligioso. Sin lugar a duda, en el futuro el estudio de la historiografía israelí ocupará un lugar muy importante en el devenir del conflicto, dados los constantes cambios a los que está siendo sometido actualmente.

\section{Referencias}

תילארשי תירבה דובכל תרבוח .רשבמ ילגאר .Alkalay, Yehuda. 1865 הלסריבוא.Fol

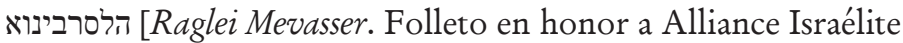
Universelle]. Belgrado: n.d.

Anderson, Benedict. 1993. Comunidades imaginadas. Reflexiones sobre el origen y la difusión del nacionalismo. México: Fondo de Cultura Económica.

Ben-Sasson, Haim Hillel, ed. 1969. Toldot Am Israel [Historia del pueblo judío]. Vol. 1. Tel Aviv: Dvir.

Benvenisti, Meron. 2000. Sacred Landscape: The Buried History of the Holy Land since 1948. Berkeley: University of California Press.

BoHm, Adolf. 1920. Die Zionistische Bewegung [El movimiento sionista]. Vol. 1. Berlín: Welt.

Dershowitz, Alan. 2003. The Case for Israel. Hoboken: John Wiley $\&$ Sons.

Dubnow, Simón. 1939. Divrei Yemei 'Am 'Olam [La historia de un pueblo eterno]. Vols. 1-2. Tel Aviv: Dvir.

Gelber, Yoav. 2007. "The History of Zionist Historiography: From Apologetics to Denial”. En Making Israel, editado por Benny Morris, 47-80. Ann Arbor: University of Michigan Press.

Gelber, Yoav. 2011. Nation and History: Israeli Historiography Between Zionism and post-Zionism. Londres: Vallentine Mitchell.

Gijón Mendigutia, Mar. 2008. "Los 'nuevos historiadores' israelíes. Mitos fundacionales y desmitificación”. Revista de Estudios Internacionales Mediterráneos, núm. 5: 27-41.

Graetz, Heinrich. 1891. History of the Jeres. Vols. 1-3. Filadelfia: The Jewish Publication Society of America.

Gruenbaum, Yitzhak. 1946. The History of Zionism. Part I: The PreHerzlian Period. Tel-Aviv: Lion the Printer for the Zionist Organization Youth Department. 
Hess, Moses. 1918. Rome and Jerusalem. A Study in Jewish Nationalism. Nueva York: Bloch.

Kalisher, Zvi Hirsch. 1964. Drishat Zion [En búsqueda de Sion]. Jerusalén: Mossad Harav Kook.

KoLATT, Israel. 1976. "Heker toldot ha-Tziyonut ve-ha-yishuv" [Sobre la investigación de la historia del yishuv y el movimiento sionista]. En Al ha-mehkar ve-ha-hoker shel toldot ha-yishuv ve-ha-Tziyonut [Sobre la investigación y el investigador de la historia del yishuv y el movimiento sionista], Catedra 1. Jerusalén: HaUniversita.

Krell, Yehuda. 2014. Páginas de odio. Historia del antisemitismo. Buenos Aires: Dunken.

Kunn, Thomas S. 2004. La estructura de las revoluciones cientificas. Traducido por Carlos Solís Santos. México: Fondo de Cultura Económica.

LEWIS, Bernard. n.d. "1834-1892-Primeras ideas y actuaciones sionistas: Alkalai, Hess, Kalisjer, Eliot, Pinsker, Bodenheimer...”. https://sites.google.com/site/misjuderias/israel/historia/18401917---moderna-ideacion-y-gestacion-del-estado-de-israel/1840--primeras-ideas-y-actuaciones-sionistas

LichtheIM, Richard. 1951. Toldot ha-Tziyonit be-Germania [Historia del sionismo en Alemania]. Jerusalén: The Sionist Library.

Liebel, Helen. P. 1971. "The Enlightenment and the Rise of Historicism in German Thought". Eighteenth-Century Studies 4(4): 359-385. https://doi.org/10.2307/2737710

Lово, Gregory J. 2009. Colombia: algo diferente de una nación. Bogotá: Universidad de los Andes.

MidEast Web. 2017. "La población árabe y judía en 'Palestina' durante el Imperio otomano y el Mandato británico. Consideraciones estadísticas y demográficas”. PorIsrael, 10 de julio de 2017. http://porisrael.org/2017/07/10/la-poblacion-arabe-y-judia-enpalestina-durante-el-imperio-otomano-y-el-mandato-britanicoconsideraciones-estadisticas-y-demograficas/

Morocutti, Pietro. 2015. "Desde la lucha entre historiografías nacionales hacia la narración-puente; el caso de Palestina/Israel”. Miscelánea de Estudios Árabes y Hebraicos, Sección Árabe-Islam 64: 75-94.

Myers, David N. y David B. Ruderman, eds. 1998. The Jerwish Past Revisited: Reflections on Modern Jewish Historians. New Haven, CT: Yale University Press. 
Neuberger, Benyamin. 1999. "Zionism”. Israel Ministry of Foreign Affairs. https://mfa.gov.il/MFA/AboutIsrael/State/Pages/ ZIONISM-\%20Background.aspx

PAPpé, Ilan. 2008. "Zionism as Colonialism: A Comparative View of Diluted Colonialism in Asia and Africa”. South Atlantic Quarterly 107(4): 611-633.

PÉrez GonzÁLEZ, Carmen y Pedro Sánchez Herráez. 2012. El conflicto palestino israelí II. Madrid: Ministerio de Defensa.

Poblete Piedrabuena, Miguel Ángel y Carlos Javier Pardo Abad. 1989. "Los modelos de colonización agrícola israelíes: el kibutz y el moshav". Ería: Revista Cuatrimestral de Geografía, núm. 1920: 202-207.

Ramos Tolosa, Jorge. 2014. “'Un país de desolación, sílices y cenizas'. El mito de Palestina como tierra virgen en el discurso sionista”. Historia Social 78: 117-134.

SÁNCHEZ Aroca, Izaskun. 2010. “¿Una tierra sin pueblo, para un pueblo sin tierra?”. https://revistasoberaniaalimentaria.wordpress.com/2010/08/23/ ¿una-tierra-sin-pueblo-para-un-pueblosin-tierra/

SAND, Shlomo. 2013. La invención de la tierra de Israel: de Tierra Santa a madre patria. Madrid: Akal.

Silber, Michael K. 2008. "Alliance of the Hebrews, 1863-1875: The Diaspora Roots of an ultra-Orthodox proto-Zionist Utopia in Palestine". The Journal of Israeli History. Politics, Society, Culture 27(2): 119-147. https://doi.org/10.1080/13531040802284031 SoKolow, Nahum. 1919. History of Zionism. Vol. 1. Londres: Longmans, Green \& Co.

Torres Prieto, Juana María. 2009. "Retórica y argumentación en la literatura polémica cristiana de los siglos II-V”. Mainake 31: 271-280.

Juan David Echeverry Tamayo es historiador por la Universidad de Antioquia y maestro en estudios en relaciones internacionales de la UNAM. Pertenece al grupo de investigación en Estudios Interdisciplinares en Historia General de la Universidad de Antioquia. Es docente con experiencia en áreas de historia y ciencias sociales, así como en manejo de bases de datos, bús- 
queda de información y modelos de educación flexible como escuela Nueva, Aceleración del Aprendizaje y Procesos Básicos, especialmente en proyectos de emergencia social y acompañamiento a víctimas del conflicto armado en Colombia. $\mathrm{Ha}$ sido ponente en Colombia, Cuba, México, Perú, Rumania y Uruguay con temas que giran alrededor de la conformación nacional en América Latina, la participación de las mujeres, las minorías y los sectores excluidos en la formación de las naciones latinoamericanas, y el conflicto palestino-israelí. Tiene una mención especial por la tesis de licenciatura "La nación: un problema conceptual” (2017) y es becario del Consejo Nacional de Ciencia y Tecnología, México.

https://orcid.org/0000-0003-2200-7046 juand.echeverry@comunidad.unam.mx 